\title{
Editorial
}

\section{From Editor-In-Chief's Desk}

\author{
Mahesh Kumar Goenka ${ }^{1}$ \\ ${ }^{1}$ Department of Gastrosciences and Liver, Apollo Gleneagles \\ Hospitals, Kolkata, India
}

J Digest Endosc 2020;11:95-96

Three months back, none of us imagined that a "viral pandemic" could turn the whole world topsy-turvy. Medical practice is one of the worst affected sectors of life both in terms of coronavirus disease 2019 (COVID-19) patients approaching hospitals in large numbers and non-COVID patients staying away.

Gastroenterology and gastrointestinal (GI) endoscopy are taking the brunt due to fear of disease transmission on part of patients as well as endoscopy health care personnel. A survey conducted by us showed that most of the endoscopists have their procedure count reduced to almost $10 \%$. Last few weeks have shown some improvement in the scenario. This is not because of reduced transmission risk but due to the fraternity becoming more knowledgeable about the disease and better prepared in terms of COVID-19 testing, rational use of personal protective equipment, and proper patient triaging. However, everyone believes that it may be several months or even years before GI endoscopy practice comes back to its pre-COVID era. It is also assumed that research and innovations in GI endoscopy will also take a back seat, and this may halt the evolution of science of GI endoscopy. Training of fellows is also suffering in the present scenario.

While these are gloomy days, there may be a silver lining in the black clouds. Certain aspects of our lives which were not getting as much attention as required, are getting more focus. For the editorial board of our journal, one such aspect is to spend more time to see that the journal achieves its aims as we enter the 11th year of its publication. As you may be aware, we transitioned to the current publishers 2 years back with an aim to have a journal with better scientific content, timely publication, and an improved overall look.
I am happy to inform you that our journal is getting articles written by authors from all across the globe. While we still have a majority of submissions from India, we did get articles from United States, United Kingdom, Germany, Japan, Greece, Thailand, Netherland, and so on (-Fig. 1). Our rejection rate has been around $50 \%$ ( - Fig. 2). We have also recently added a video section to depict rare or unusual endoscopic procedures.

We have been able to publish our issues on time. Our last issue was totally dedicated to COVID-19 and this was possibly the only endoscopy-oriented journal, where an issue had as many as 27 articles covering all aspects of this new deadly disease.

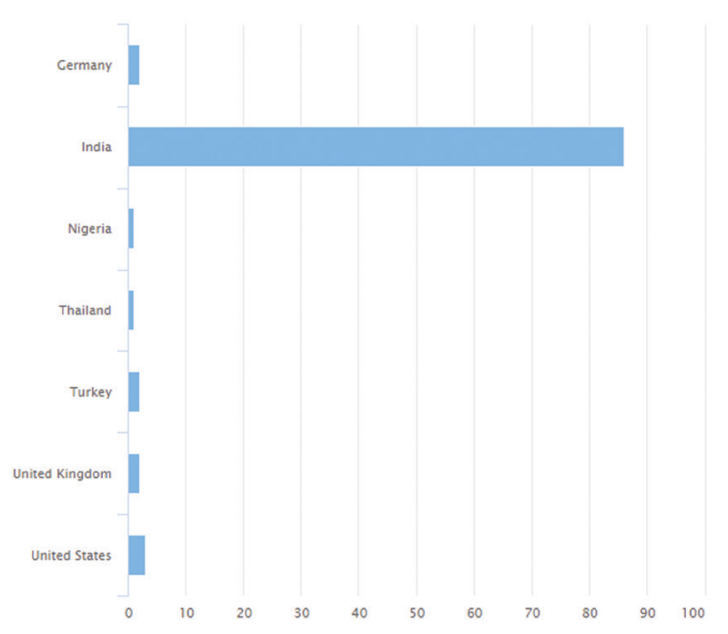

Fig. 1 Submission by country between January 2020 and June 2020.
Address for correspondence Mahesh Kumar Goenka, MD, DM, MNAMS, FACG, FASGE, AGAF, MRCP, Department of Gastrosciences and Liver, Apollo Gleneagles Hospitals, Kolkata 700054 , India (e-mail: mkgkolkata@gmail.com).
DOI https://doi.org/

10.1055/s-0040-1714047 ISSN 0976-5042.
C2020 Society of Gastrointestinal Endoscopy of India
License terms

(요 (1) $\Theta \circledast$ 


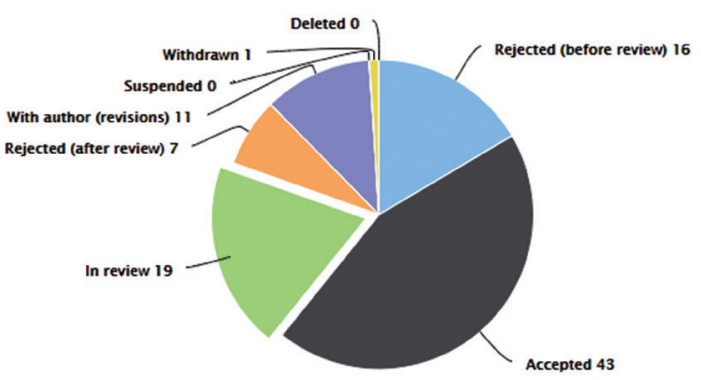

Fig. 2 Manuscript decision between January 2020 and June 2020 .

The Editorial board aims to improve the indexing of our journal, increase the frequency of publication, and have a better quality of articles. We would require more research articles, reviews, commentaries, videos, and images. We wish to decrease the publication of case reports except for very rare or unique cases.
All these would be possible only by co-operation and active involvement of our reviewers and editorial board members. A "journal" I believe, is as good as its reviewers and board members. A fast review process, irrespective of the outcome in terms of acceptance, resubmission, or rejection, is an incentive to scientists to send their work to a journal. We have started to send articles for review only to members who are willing to do it fast. We are also contacting them offline to help us in moving ahead.

I am sure with the involvement of our society members, reviewers, potential authors, and editorial board, we would be able to change gears and take our journal to a higher level. I firmly believe that the official Journal of a professional Society is a very important vertical and needs to be nourished with care and all the passion it deserves.

\section{Conflict of Interest}

None declared. 